\title{
Dissimilarity of mechanisms for evocation of escape and avoidance responding in dogs
}

\author{
RONALD N. EHRMAN and J. BRUCE OVERMIER \\ Untversity of Minnesota, Minneapolis, Minnesota 55455
}

\begin{abstract}
Two groups of dogs were compared on the ability of an aversive Pavlovian CS to evoke a negatively reinforced instrumental response. For one group, the instrumental training was avoidance; for the other, escape. When presented alone, the CS evoked the instrumental response only from the avoidance group. Failure of the CS to evoke the response from the escape group poses difficulties for theories which characterize the initiation of avoidance responses as "escapes" from CS.
\end{abstract}

Most generalized two-process theories of avoidance behavior are derived from analyses of discriminated, discrete trial avoidance acquisition under the method of emergence (Solomon \& Brush, 1956). In such a procedure, if the subject fails to avoid, it must (can) escape from the aversive US. These theories assert that on early trials two things are learned concurrently: (a) the animal learns an instrumental response which is reinforced by termination of the noxious US, and (b) an anticipatory conditioned response (CR, commonly called "fear") is conditioned to the SD through imbedded "Pavlovian" pairings of the SD and US. The CR is thought to be a fractional anticipatory component of the response to the original US. Thus, on later trials, this anticipatory $\mathrm{CR}$ itself comes to evoke the instrumental response because the $C R$ has stimulus and motivational properties similar to those of the US. Because this evoked response occurs before the US, the US is avoided. Of importance for the present experiment is the assumption that the mechanism whereby these avoidance responses are evoked by the SD-elicited $\mathrm{CR}$ is closely related to the mechanism whereby escape responses are evoked by the US; Kimble (1961) Miller (1935), Schoenfeld (1950), and others concisely captured this common conceptualization in their discussions of avoidance-response evocation by referring to the avoidance response as an escape from the $\mathrm{SD}$, or the $\mathrm{SD}^{\mathrm{D}}$ elicited fractional anticipatory pain, or "fear" CR.

May (1948) performed an experiment which has become the textbook prototype (see Kimble, 1961) for demonstrating the two subprocesses presumed to be taking place in the development of avoidance (cf. Mowrer, 1947). May's experiment had three

This research was supported in part by Grant $\mathrm{MH}-13,558$ to J.B.O. Requests for reprints should be sent to J. Bruce Overmier, Elliott Hall, University of Minnesota, Minneapolis, Minnesota 55455. phases. In the first phase, rats were taught to shuttle across a barrier to escape shock; no warning stimulus was utilized. In the second, an experimental group received Pavlovian pairings of a buzzer and shock while confined to one side of the shuttlebox; control groups were not given such buzzer-shock pairings. And finally, in the shuttlebox, test presentations of the buzzer were given. Most of the experimental animals responded to the buzzer by crossing the barrier, whereas few of the control group responded. The essence of May's interpretation of his results was that the CS had come to evoke the same neural consequences as the US, but to a lesser degree. During test trials, this CS-elicited internal reaction, being similar to the one evoked by the shock, resulted in responding similar to that which had been learned to the shock.

This kind of two-process explanation for avoidance responses can be referred to as the "generalization through common elements" position. "Common elements" explanations of avoidance behavior have broad acceptance. However, there is evidence to suggest that the mechanisms underlying the escape and avoidance responses are not this closely related. For example, Lord, King, and Pfister (1976) recently reported that chronic peripheral sympathectomy in mature rats impaired escape behavior but not avoidance behavior (Experiment 2 vs. Experiment 5). Furthermore, Bolles (1969) and Bolles, Stokes, and Younger (1966) have shown that the emergence of avoidance responses is not necessarily facilitated when the avoidance and escape responses are topographically identical, as compared to when they are different. Indeed, Zielinsky and Soltysik (1964) have provided evidence that prior escape training may impair subsequent acquisition of the same behavior as an avoidance response. Finally, Fonberg (1962) showed that, after an avoidance response was established to an $\mathrm{S}^{\mathrm{D}}$ paired with a very brief duration US (which could therefore not be 
escaped), prolonged presentations of the US alone would not evoke that response.

Each of these experimental outcomes is incongruent with expectations based upon the concept of a common response-evoking mechanism for avoidance and escape responses which would predict positive transfer. We believe this indicates that the $\mathrm{S}^{\mathrm{D}}$ does not have response-evoking properties (acquired through "Pavlovian" conditioning) highly similar to those of the US.

The only strong data providing support for the "common elements"' are from May's 1948 experiment. A careful reexamination of that experiment suggests a possible confounding. In that experiment, the immediate consequences of intertrial responses were to postpone presentations of the next scheduled shock; thus, intertrial responses were functionally equivalent to avoidance responses (cf. Sidman, 1953). Therefore, May's purported demonstration of transferred control by a shock-paired CS over a previously trained instrumental escape response may actually have been control over an avoidance response, a well-known phenomenon (e.g., Rescorla \& Solomon, 1967; Solomon \& Turner, 1962). Indeed, Rescorla and LoLordo (1965) have shown explicitly that a shock-paired CS will elicit a separately established Sidman avoidance response.

The purpose of the present experiment was to see if the response evocation by a CS for shock (transfer of control) reported by May (1948) would result when procedures were used which would insure that the escape response did not also function as an avoidance. A secondary purpose was to compare the amount of transfer of control of an escape response with that of an equally practiced explicitly trained avoidance response. If the response-evoking mechanisms of escape and avoidance responses are highly similar, similar transfer of control of the respective responses to the Pavlovian CSs should be observed in testing. However, if the transfer of control observed by May was an artifact of the unrecognized avoidance contingency, then rather poor transfer of control, if any, would be expected in the escape-trained group.

\section{METHOD}

\section{Subjects}

Eighteen experimentally naive adult mongrel dogs, $38-48 \mathrm{~cm}$ all at the shoulder, with full-ration body weights at $12-13 \mathrm{~kg}$, and obtained from the University of Minnesota Animal Hospital, served as subjects. They were maintained on a free food and water diet. During the course of the experiment, six dogs were discarded because of health or apparatus failure. This left two groups of six dogs each.

\section{Apparatus}

All phases were carried out in a two-way shuttlebox with two black compartments separated by an adjustable barrier and a removable gate which could completely isolate the two compartments. Each compartment was $1.4 \times 0.6 \times 1.0 \mathrm{~m}$ and had ceilings made of hardware cloth. Above the hardware cloth ceiling of each compartment were mounted a 7.5-W lamp, a $150-\mathrm{W}$ lamp, and a speaker. Turning off of the 150-W lamp was used to provide a visual sıgnal ( $\mathrm{SD}^{\mathrm{D}}$ ). The auditory $\mathrm{CS}$ stımuli were 200 - and $2,900-\mathrm{Hz}$ square-wave tones at $15 \mathrm{~dB}$ above the continuous $70-\mathrm{dB}$ white-noise background. $A$ one-way mirror, mounted in the front of each chamber, permitted continuous observation. The US was a $4.5-\mathrm{mA}$ electric shock administered through a grid floor consisting of $3.2-\mathrm{cm}$ aiumınum bars placed $1.6 \mathrm{~cm}$ apart $\mathrm{A}$ commutator shifted the polarity pattern of the bars 6 times/sec. Latencies of barrier jumping response were measured from signal onset to the nearest .1 sec using a timer controlled by two photocell relays in each compartment. In all phases, stimulus duration and contingencies were controlled by automatic relay crrcuitry located in another room

\section{Treatments}

Training for the two groups differed only in the first phase of three successive phases. In Phase I, one group received discrete tral shock-escape training (escape group); the other recerved discrete trial shock-avoidance traınıng (avoidance group). Phase II for both groups was discriminative defensive Pavlovian cond. tioning with the auditory CSs and shock US Phase III for both groups consisted of discrete trial test presentations in the shuttlebox of all three stimuli used in the previous phases; shock was not administered in this final phase All sessions began with at 5 -min period of adaptation to the apparatus

\section{Instrumental Training-Phase I}

Avoidance group. In the aroldance group, each subject was given discrete trial instrumental avoudance training. A trial was initiated by the onset of the visual $S^{D}$. If the dog jumped within $10 \mathrm{sec}$, the $\mathrm{S}^{\mathrm{D}}$ was termınated and no shock was presented; if it failed to respond within $10 \mathrm{sec}$, shock came on and remained on until it hurdled the barrier. If no response occurred within $60 \mathrm{sec}$, the trial automatically terminated. Upon trial termination, the gate was lowered isolating the dog within one compartment of the shuttlebox.

Escape group The detals of the instrumental escape training are of critical importance. Each trial was initiated with the visual $\mathrm{S}^{\mathrm{D}}$, but its presentation was simultaneous with the onset of the shock. That 1s, the $S^{1}$ did not ignal hock onset, rather, 11 was presented concurrently with the hoch to equate the two groups on the number of isual sumulu, presentations in Phase 1. The $\mathrm{S}^{\mathrm{l}}$ and shock were both terminated by either a shuttle response or the lapse of $60 \mathrm{sec}$. Upon termination of the trial, the gate was completely lowered, thereby isolating the dog within one compartment.

Each subject received 90 instrumental trainıng trials distributed over 4 days, with $22,23,22$, and 23 trials per training session. (Because of a programming difficulty, the 90 trials were distributed over 8 days for one dog.) Overall, the avoidance group averaged $68 \%$ avoidances with $91 \%$ on the last day; the escape group averaged $95 \%$ escape with $100 \%$ on the last day.

For both groups, time between each trial was divided into two distinct sequential periods: an isolation period and an intertrial interval. During the isolation period, the subjects were prevented from crossing the barrier, durng the intertral interval, the subjects could cross the barrier (ITR).

The period of ssolation was of variable duration ranging from a maximum of $120 \mathrm{sec}$, at the start of each day of tramng, to a possible minimum of $10 \mathrm{sec}$. The length of the ssolation perrod was a function of the number of responses, if any, during the preceding intertrial interval (ITI). If zero ITRs occurred during the previous ITI, the isolation period of the following trial was decreased according to a preestablished schedulte of decreases

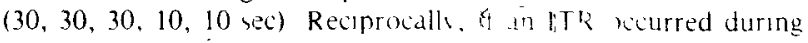


the previous ITI, the isolation period of the following trial was increased according to the same schedule. The mean duration of isolation was approximately $55 \mathrm{sec}$. It is important to note that, in contrast to May's experiment, ITRs here did not affect the time of occurrence of the next scheduled trial, but only the length of isolation subsequent to the next trial. Bolles and Popp (1964) have shown that such an arrangement will not support responding. Therefore, no meaningful avoidance contingency was present here as there was in the May experiment.

The intertrial interval was determined by a variable time $3-\mathrm{min}$ schedule (VT $3-\mathrm{min}$ ). The first $30 \mathrm{sec}$ of this interval entailed raising the gate approximately $28 \mathrm{~cm}$ above the fixed barrier. This permitted the dog to cross over the barrier, but only with some difficulty. After this, the gate was fully withdrawn until initiation of the next trial.

The reason for using this complicated schedule, involving isolation which prevented responding and partial gate withdrawal which retarded responding, was to maintain in both groups a low frequency of ITRs which might confound our response measurements in testing. In this, the procedure was quite successful. The two groups did not differ in total ITRs per ITI over all 90 trials (Mann-Whitney $U=15, p \cong .70$ ) or on the last day of training $(U=14, p \cong .60)$. The overall mean number of ITRs per ITI on the last day was only .69, despite the fact that some dogs had a strong preference for one side of the shuttlebox.

\section{Pavlovian Conditioning-Phase II}

Two discriminative Pavlovian conditioning sessions were given to each dog on consecutive days. During each conditioning session, the dog was confined to one side of the shuttlebox and could neither escape nor avoid. The compartment in which the dog was confined on the first day of conditioning was determined randomly with conditioning on the second day performed in the other compartment of the shuttlebox. Each Pavlovian conditioning session consisted of 30 trials, 15 to each auditory stimulus (CS,$+ \mathrm{CS}-$ ), presented in a mixed counterbalanced order. The $\mathrm{CS}+$ tone was presented for $10 \mathrm{sec}$ followed by a $.5 \mathrm{-sec}$ shock, with the CS + and the US terminating together. The CS - tone was presented alone for $10 \mathrm{sec}$ and was never followed by shock. The intertrial interval was determined by a variable time 120 -sec schedule. The choice of tone as CS + was counterbalanced within each group.

\section{Transfer Tests-Phase III}

The Pavlovian stimuli and the SD were tested for their ability to evoke the previously trained escape or avoidance response. Three days of these transfer of control tests were conducted in the shuttlebox with the isolation gate removed. There were 24 nonreinforced test trials on each day, eight to each stimulus $\left(\mathrm{S}^{\mathrm{D}}, \mathrm{CS}+, \mathrm{CS}-\right.$ ) presented in a mixed counterbalanced order $\left(\mathrm{SD}^{\mathrm{D}}, \mathrm{SD}, \mathrm{CS}-, \mathrm{CS}+, \mathrm{CS}-, \mathrm{CS}+, \mathrm{SD}^{\mathrm{D}} \mathrm{CS}+, \mathrm{CS}+, \mathrm{CS}-\right.$, $\left.\mathrm{CS}-, \mathrm{S}^{\mathrm{D}}, \mathrm{CS}+, \mathrm{SD}^{\mathrm{D}}, \mathrm{S}^{\mathrm{D}}, \mathrm{CS}+, \mathrm{CS}-, \mathrm{CS}+, \mathrm{CS}+, \mathrm{S}^{\mathrm{D}}, \mathrm{CS}-\right)$, using the same procedure and contingencies previously used during instrumental training. A barrier jumping response terminated the test stimulus presentation. If no response occurred, the trial was automatically terminated and a $30-\mathrm{sec}$ latency was assigned.

\section{RESULTS}

Daily mean response latencies of barrier jumping to each of the stimuli during transfer tests (Phase III) were the primary data. These were subjected to analysis of variance for repeated measures.

The escape- and avoidance-trained groups differed in their overall levels of responding and in their patterns of responding to the three stimuli during the transfer test sessions, Groups $\mathrm{F}(1 / 10)=33.87$,

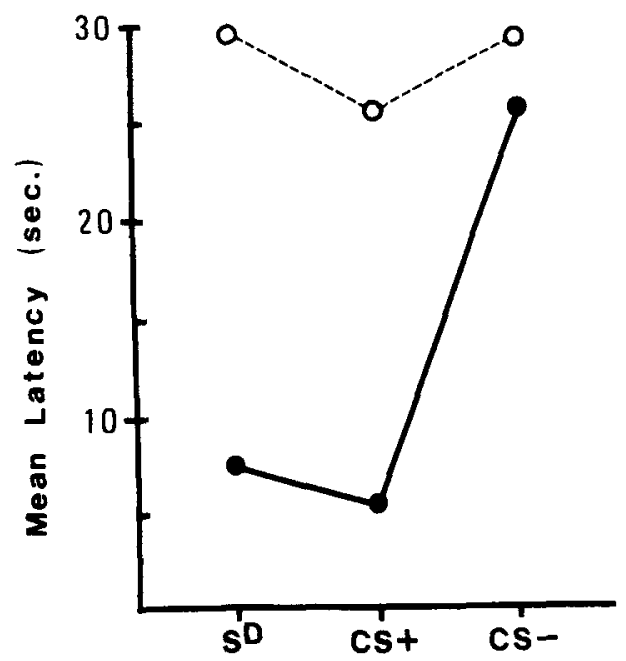

Figure 1. Mean over 3 test days of latency of response to each test stimulus by the escape-trained group (open circles and dashed lines) and the avoidance-trained group (solid dots and lines). Each point represents 24 observations.

Stimuli $F(2 / 20)=16.39$, and Groups by Stimuli $\mathrm{F}(2 / 20)=11.05$, all $\mathrm{p}<.001$. The observed patterns of responding to the stimuli were consistent over days, Days $F(2 / 20)=2.34$, Groups by Days $F<1$, Stimuli by Days $F<1$, and Groups by Stimuli by Days $F<1$, all n.s. Figure 1 presents a summary graph of the mean latencies of response for each group under each test stimulus condition.

The avoidance-trained subjects continued to respond to the original $\mathrm{SD}$ with short latencies during transfer testing. Importantly, in the avoidance group, the $\mathrm{CS}+$ tone immediately and reliably evoked the previously trained avoidance response; indeed, on only 1 of $144 \mathrm{CS}+$ presentations did an avoidance trained dog fail to respond. In fact, the mean latency of responding to CS + was less than that to the SD on every test day, though not significantly so. These data indicate that the transfer to the CS + of control of the shuttle response was immediate and closely resembled the level of control previously established to the SD by explicit avoidance training.

The transfer of control of the avoidance response was also discriminative. This is revealed by comparison to the absence of control exercised by the CS - . Responding to the CS - was slow and unreliable. Responding evoked by the SD and the CS + was faster than that evoked by the CS - , which approached the arbitrary maximum limit of $30 \mathrm{sec}, \mathrm{ts}(20)>5.95$, both ps $<.001$.

For the escape-trained subjects, the $\mathrm{SD}^{\mathrm{D}}$ generally failed to evoke the previously trained escape response during transfer testing. More importantly, in the escape group, the CS + also failed to evoke and control the escape response; indeed, only two of the six subjects in the escape group ever responded 
during a CS + presentation, and one of these did so only once. ${ }^{\prime}$ The mean latencies of responding to all three of the stimuli during the transfer test sessions approached the arbitrary maximum limit, and there were no significant differences in responding among them. These data indicate that transfer of control of the shuttle response previously established by strictly escape training did not occur.

Finally, between-group comparisons revealed that the avoidance group's responses to the SD and to the CS + , respectively, were considerably faster and more reliable than were the escape group's responses to these stimuli, $\operatorname{ts}(28)>5.50$, both ps $<.001$. The two groups did not differ in their responding to CS-.

\section{DISCUSSION}

A Pavlovian CS + can exercise immediate discriminative transfer of control over a previously trained avoidance response but not a previously trained escape response-at least in dogs. This observation stands in sharp contrast to May's (1948) report of transfer of control of escape behavior, which has been a cornerstone for two-process theorizing. However, we have already noted that May's interpretation was unwarranted, given the presence of an unrecognized avoidance contingency. Although unrecognized as such, May's report makes clear that the subjects were, indeed, sensitive to the contingency and sometimes "postponed" the next shock-escape trial for several minutes. In the present experiment, intertrial responses were not effective in postponing the next scheduled trial, and we observed essentially no transfer of control of the escape response to the Pavlovian CS + . This failure of transfer in escape-trained subjects cannot be attributed to inadequate Pavlovian conditioning because that treatment did yield effective transfer of control in the avoidance trained group; indeed, their latencies to the Pavlovian CS + were typically as fast or faster than to the SD, the stimulus to which the avoidance response had been explicitly trained.

One extreme subject is illustrative of the CS + 's power to control behavior in subjects with a history of avoidance training. Across the 3 days of testing, its responses to the $\mathrm{SD}$. averaged $23.4,26.7$, and $30.0 \mathrm{sec}$ (i.e., extinguished). Meanwhile, the CS + continued to control a vigorous jumping response all 3 days, with latencies averaging $13.3,5.5$, and $9.3 \mathrm{sec}$.

Tests for the control exerted by the SD stimulus in each group revealed that SD controlled jumping for the avoidance group but not for the escape group. That the $\mathrm{SD}$ did not control responding in the escape groups is not surprising, given that during instrumental training the SD and US were presented simultaneously. Historically, such a stimulus condi- tioning relationship has not been found to result in excitatory conditioning to the stimulus (Kimble, 1961).

The occurrence of transfer to the CS + tone of control of the jumping response in the avoidance group but not in the escape group cannot be handled by any simple stimulus generalization notion. There is no compelling reason to believe that turning off a light (SD) and onset of a loud tone (CS+) have more stimulus elements in common than do electric shocks (US) and loud tone. (Even if this were so, it could not account for the extreme case just mentioned above.) But the "common elements" typically invoked to explain avoidance responding are conditioned fractional components of the shockelicited reaction (Kimble, 1961). Failure to observe "avoidance" responding to the tone CS + suggests that such common elements, if any, play little or no role in the emergence of avoidance responses. The present results establish the importance to the transferof-control phenomenon of stimulus relationships in the instrumental phase appropriate for excitatory Pavlovian conditioning, i.e., a predictive relation between the SD and the US. Transfer to Pavlovian CSs of control of responding is apparently dependent upon a commonality arising from the "anticipatory" nature of avoidance behavior.

That termination of the CS may function to reinforce occurrences of the avoidance response was not at issue here. Though potentially they might have, the present data do not speak to the issue because: (a) the avoidance-trained group responded to CS + presentations on Day 1 with essentially "asymptotic" latencies, while (b) the escape group did not generate responses that could be "reinforced" by CS + termination.

The obtained qualitative differences between the two groups in the patterns of responding to the three test stimuli demonstrate that (a) escape and avoidance training result in mechanisms of response evocation and control which differ markedly from one another, and (b) the mechanism of response evocation and control involved in avoidance behavior is closely allied with Pavlovian conditioning mechunisms. The present results confirm and extend the important observations of Bolles (1969; Bolles et al., 1966) and Fonberg (1962) on the basic functional differences between escape and avoidance responses. Clearly, avoidance responding is not simply instrumental USescape responding generalized to the defensive Pavlovian CS +.

\section{REFERENCES}

Bolles, R. C. Avoidance and escape learning: Simultaneous acquisition of different responses. Joumal of Comparative and Physiological Psychology, 1969, 68, 355-358.

Bolizs, R. C., \& Popp, R. J. Parameter affecting the acquisition of Sidman avoidance. Joumal of the Experimental Anulysis of Behavior, 1964, 7, 315-321. 
Bolies, R. C., Stokes, L. W., \& Younger, M. S. Does CS termination reinforce avoidance behavior? Joumal of Compurative and Physiological Psychology, 1966, 62, 201-207.

FonBERG, E. Transfer of the conditioned avoidance reaction to the unconditioned noxious stimuli. Acta Biologiae Experimentalis, 1962, 22, 251-258.

KImBle, G. A. Hilgard and Marquis: Conditioning and learning (2nd ed.). New York: Appleton-Century-Crofts, $1 \% 1$.

Lord, B. J., King, M. G., \& Prister, H. P. Chemical sympathectomy and two-way escape and avoidance learning in the rat. Journal of Comparative and Physiological Psychology, 1976, 90, 303-316.

MAY, M. A. Experimentally acquired drives. Joumal of Experimental Psychology, 1948, 38, 66-77.

Mrler, N. E. A reply to "Sign-Gestalt or conditioned reflex." Psychological Review, 1935, 42, 280-292.

Mowrer, O. H. On the dual nature of learning-a reinterpretation of "conditioning" and "problem solving." Harvard Educational Review, 1947, 17, 102-108.

ResCorLA, R. A., \& LoLoRdo, V. M. Inhibition of avoidance behavior. Joumal of Comparative and Physiological Psychology, 1965, 59, 406-412.

Rescorla, R. A., \& Solomon, R. L. Two process learning theory: Relationships between Pavlovian conditioning and instrumental learning. Psychological Review, 1967, 74, 151-182.
Schoenfeld, W. N. An experimental approach to anxiety, escape, and avoidance behavior. In P. N. Hoch, \& J. Zubin (Eds.). Anxiety. New York: Grune \& Stratton, 1950. Pp. 70-99.

Sidman, M. Avoidance conditioning with brief shock and no exteroceptive warning signal. Science, 1953, 118, 157-158.

Solomon, R. L., \& Brush, R. S. Experimentally derived conceptions of anxiety and aversion. In M. R. Jones (Ed.), Nebraska Symposium on Motivation. Lincoln: University of Nebraska Press, 1956.

Solomon, R. L., \& Turner, L. H. Discriminative classical conditioning in dogs paralyzed by curare can later control discriminative avoidance responses in the normal state. Psychological Review, 1962, 69, 202.219.

Zielinski, K., \& Soltysik, S. The effect of pretraining on the acquisition and extinction of the avoidance reflex. Actu Biologiae Experimentalis, 1964, 24, 73-87.

\section{NOTE}

1. These observations have now been informally replicated in our laboratory in three additional escape-trained dogs.

(Received for publication January 26, 1976; revision accepted April 12, 1976.) 